\title{
Control of mitochondrial gene expression in the aging rat myocardium
}

\author{
Christophe M.R. LeMoine, Grant B. McClelland, Carrie N. Lyons, \\ Odile Mathieu-Costello, and Christopher D. Moyes
}

\begin{abstract}
Aging induces complex changes in myocardium bioenergetic and contractile properties. Using $\mathrm{F}_{344 \mathrm{BNF}_{1}}$ rats, we examined age-dependent changes in myocardial bioenergetic enzymes (catalytic activities and transcript levels) and mRNA levels of putative transcriptional regulators of bioenergetic genes. Very old rats (35 months) showed a $22 \%$ increase in ventricular mass with no changes in DNA or RNA per gram. Age-dependent cardiac hypertrophy was accompanied by complex changes in mitochondrial enzymes. Enzymes of the Krebs cycle and electron transport system remained within $15 \%$ of the values measured in adult heart, significant decreases occurring in citrate synthase $(10 \%)$ and aconitase (15\%). Transcripts for these enzymes were largely unaffected by aging, although mRNA levels of putative transcriptional regulators of the enzymes (nuclear respiratory factor (NRF) 1 and $2 \alpha$ subunit) increased by about 30\%$50 \%$. In contrast, enzymes of fatty acid oxidation exhibited a more diverse pattern, with a $50 \%$ decrease in $\beta$-hydroxyacylCoA dehydrogenase (HOAD) and no change in long-chain acyl-CoA dehydrogenase or carnitine palmitoyltransferase. Transcript levels for fatty acid oxidizing enzymes covaried with HOAD, which declined significantly by $30 \%$. There were no significant changes in the relative transcript levels of regulators of genes for fatty acid oxidizing enzymes: peroxisome proliferator-activated receptor- $\alpha(\operatorname{PPAR} \alpha)$, PPAR $\beta$, or PPAR $\gamma$ coactivator- $1 \alpha(\operatorname{PGC}-1 \alpha)$. There were no changes in the mRNA levels of Sirt1, a histone-modifying enzyme that interacts with PGC-1 $\alpha$. Collectively, these data suggest that aging causes complex changes in the enzymes of myocardial energy metabolism, triggered in part by NRF-independent pathways as well as post-transcriptional regulation.
\end{abstract}

Key words: PGC-1a, fatty acid oxidation, nuclear respiratory factor (NRF), PPAR, coactivator, transcriptional regulation.

Résumé : Le vieillissement induit des changements complexes dans les propriétés bioénergétiques et contractiles du myocarde. Nous avons examiné les changements affectant les enzymes bioénergétiques du myocarde (activité catalytique et niveau de transcrits) et les niveaux d'ARNm de régulateurs transcriptionnels présumés des gènes codant ces enzymes

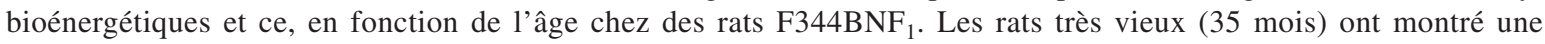
augmentation de la masse ventriculaire de $22 \%$ sans changement de rapports ADN/g ou ARN/g de tissu. L'hypertrophie cardiaque dépendante de l'âge était accompagnée de changements complexes affectant les enzymes mitochondriales. Les enzymes du cycle de Krebs et du système de transport d'électrons sont demeurées à l'intérieur d'une limite de $15 \%$ des valeurs mesurées chez le rat adulte, une diminution significative de la citrate synthase (10\%) et de l'aconitase (15\%) étant observée. Les transcrits de ces enzymes n'étaient globalement pas affectés par le vieillissement, même si les niveaux d'ARNm de régulateurs transcriptionnels présumés de ces enzymes (NRF1 et NRF2- $\alpha$ ) ont augmenté d'environ 30-50 \%. En revanche, les enzymes impliquées dans l'oxydation des acides gras ont montré des patrons de variation plus diversifiés, dont une diminution de $50 \%$ de la quantité d'hydroxyacyl-CoA déshydrogénase $\beta$ (HOAD), sans changement dans les quantités de déshydrogénase d'acyls-CoA à longue chaîne ou de carnitine palmitoyltransférase. Les niveaux de transcrits des enzymes impliquées dans l'oxydation des acides gras ont varié de concert avec la HOAD, présentant une diminution significative de $30 \%$. Il n'y a pas eu de changements significatifs dans les niveaux relatifs des transcrits de régulateurs des gènes codant ces enzymes d'oxydation des acides gras : les récepteurs PPAR $\alpha$, PPAR $\beta$ ainsi que le coactivateur-1 $\alpha$ du PPAR $\gamma($ PCG-1 $\alpha)$. Les niveaux d'ARNm de Sirt1, une enzyme de modification des histones qui interagit avec PCG- $1 \alpha$, n'ont pas non plus changé. L'ensemble de ces résultats suggère que le vieillissement cause des changements complexes dans les enzymes du métabolisme énergétique du myocarde, amorcés en partie de façon indépendante des voies de NRF ainsi que par des mécanismes de régulation post-transcriptionnels.

Mots clés : PGC-1a, oxydation des acides gras, NRF, PPAR, coactivateur, régulation de la transcription.

[Traduit par la Rédaction]

Received 28 July 2005. Revision received 20 October 2005. Accepted 24 October 2005. Published on the NRC Research Press Web site at http://bcb.nrc.ca on 6 April 2006.

C.M.R. LeMoine, C.N. Lyons, and C.D. Moyes. ${ }^{\mathbf{1}}$ Department of Biology, Queen's University, Kingston, ON K7L 3N6, Canada. O. Mathieu-Costello. Department of Medicine, University of California San Diego, San Diego, CA 92093-0623, USA.

G.B. McClelland. Department of Biology, McMaster University, Hamilton, ON L8S 4K1, Canada.

${ }^{1}$ Corresponding author (e-mail: moyesc@biology.queensu.ca). 


\section{Introduction}

The adult mammalian heart relies on lipid oxidation to provide about $65 \%$ of its energy demands (Van der Vusse et al. 1992). The energy is produced when the mitochondrial $\beta$-oxidation pathway metabolizes fatty acids derived from circulating lipids. As one of the most aerobic tissues, mammalian heart possesses a relatively high mitochondrial capacity and abundant enzymes associated with fatty acid transport and oxidation. Aging causes many changes in the energy metabolism of the heart. The aging myocardium shifts its fuel preference away from fatty acid oxidation (FAO) toward carbohydrate oxidation, which is a reversion to the neonatal state (Allard et al. 1994; Sambandam et al. 2002). This change in fuel preference is typically paralleled by a reorganization of mitochondrial metabolism, including a shift in the gene expression and relative activities of fatty acid oxidizing enzymes (Lee et al. 2002, Hansford and Castro 1982; Wanagat et al. 2002). This switch in fuel preference is thought to be maladaptive and contribute to the contractile dysfunction (Barger and Kelly 1999).

The mitochondrial changes are only 1 element of the extensive myocardial remodelling with age. The ventricle structure changes because of hypertrophy of some cardiomyocytes, death of others, and the resulting fibrosis, which culminate in reduced ventricular performance (Besse et al. 1993; Swynghedaw et al. 1995; Kajstura et al. 1996). The age-dependent hypertrophy has parallels with the changes seen in cardiopathologies, including hypertensive hypertrophy (Sack and Kelly 1998; Leary et al. 2002; Davila-Roman et al. 2002; Finck and Kelly 2002; Iemitsu et al. 2002; Lehman and Kelly 2002; de las Fuentes et al. 2003).

Expression profiling studies in aging myocardium reveal changes in mRNA levels for suites of genes associated with the stress response, cell death, and signal transduction (Bodyak et al. 2002). Studies exploring the regulatory basis of the bioenergetic remodelling of the heart, reflected in mitochondrial losses and shifts in fuel preference, have focused on transcriptional regulators. One coactivator, PGC- $1 \alpha$, is considered to be a master regulator of mitochondrial proliferation and function, acting through transcription factors that regulate networks of respiratory genes, including nuclear encoded mitochondrial enzymes and the regulators of mitochondrial DNA replication and transcription (Knutti and Kralli 2001; Puigserver and Spiegelman 2003; Wu et al. 1999). PGC-1 $\alpha$ coactivates the nuclear receptors PPARs (peroxisome proliferator-activated receptors $\alpha, \beta / \delta$, and $\gamma$ ) (Barger and Kelly 2000; Gilde and van Bilsen 2003) and the nuclear respiratory factor 1 and 2 (NRF1 and 2) (Wu et al. 1999; Puigserver and Spiegelman 2003).

The PPARs have a prominent role in the regulation of most nuclear-encoded mitochondrial enzymes associated with FAO (Aoyama et al. 1998; Djouadi et al. 1999; Barger and Kelly 2000; Muoio et al. 2002; Gilde and van Bilsen 2003; Cheng et al. 2004), whereas the NRFs regulate the transcription of several mitochondrial proteins necessary to mitochondrial biogenesis and oxidative metabolism (Evans and Scarpulla 1989; Carter et al. 1992; Martin et al. 1996; Gugneja and Scarpulla 1997; Vallejo et al. 2000; Lezza et al. 2001; Mootha et al. 2004). PGC-1 $\alpha$ can also exert effects that are independent of PPARs and NRFs. It is subject to post-translational regulation (Puigserver et al. 2001; Rodgers et al. 2005). Recently, PGC-1 $\alpha$ was also shown to interact with an NADHdependent histone-remodelling enzyme, Sirt1 (Rodgers et al. 2005), affecting the expression of glycolytic genes. PPARs and NRFs are also regulated in ways that are independent of PGC-1 $\alpha$. For example, PPAR DNA binding activity is affected by regulatory ligands (Barger and Kelly 2000; Gilde and van Bilsen 2003), and NRFs are subject to covalent modification (Martin et al. 1996; Gugneja and Scarpulla 1997; Vallejo et al. 2000).

Collectively, PGC- $1 \alpha$ and its network of regulators are thought to help maintain the stoichiometric relations of mitochondrial enzymes, ensuring that they increase or decrease stoichiometrically. Much less is understood about the mechanisms by which the stoichiometric relations among mitochondrial enzymes are changed, as is seen in the senescent and hypertrophic heart undergoing changes in fuel preference. In this study, we compared adult rats (12 months) with very old rats (36 months) to investigate the age-associated changes in the enzymatic and transcriptional machinery of mitochondrial metabolism of the rat cardiac muscle.

\section{Materials and methods}

\section{Animals and tissue collection}

Adult male F1 hybrid F344 × Brown Norway $($ F344BNF 1 ) rats (Harlan Sprague Dawley Inc. Indianapolis, Ind.) were maintained, 2-3 in each cage, in a room maintained at constant temperature in a $12 \mathrm{~h}: 12 \mathrm{~h}$ light:dark cycle. The subjects had ad libitum access to untreated tap water and standard chow (Harlan Teklad 8604). This hybrid strain of rat has a reduced incidence of pathologies associated with aging and therefore an increased longevity, which makes it an interesting mammalian model in which to study the effect of aging (Lipman et al. 1996). The present study was conducted in a pathogen-free facility accredited by the American Association of Accreditation of Laboratory Animal Care; in addition, it was approved by the Animal Subjects Committee, University of San Diego, Calif.

Cardiac muscles were collected from rats from 2 age groups, adult (12 months) and very old (35-36 months). The animals were weighed and then anaesthetized with 40-70 mg pentobarbital. The heart was excised, weighed, flash-frozen in liquid nitrogen, and stored in cryovials at $-80{ }^{\circ} \mathrm{C}$. Subsequently, the tissue was powdered with a mortar and pestle in liquid nitrogen and stored at $-80{ }^{\circ} \mathrm{C}$.

\section{Enzyme assays}

Powdered tissues were homogenized in a 1:20 dilution of extraction solution (20 mmol Hepes/L, $1 \mathrm{mmol}$ EDTA/L, $0.1 \%$ Triton $\mathrm{X}-100, \mathrm{pH} 7.2)$ using a glass homogenizer. Specific activities of the different enzymes on 96-well plates were measured using a SpectraMAX Plus spectrophotometer (Molecular Devices Corp., Sunnyvale, Calif.) and assays described by Moyes et al. (1997) unless otherwise noted: cytochrome c oxidase (COX), isocitrate dehydrogenase (IDH), aconitase (ACON) (Gardner et al. 1994), citrate synthase (CS), $\beta$-hydroxyacyl-CoA dehydrogenase (HOAD), carnitine palmitoyltransferase (CPT) (McClelland et al. 2004), and long-chain acyl-CoA dehydrogenase (LCAD) (Nadal-Ginard et al. 2003). 
Table 1. List of primers and target rat sequences used for the RT-PCR amplification of the probes used in northern blotting analysis.

\begin{tabular}{|c|c|c|}
\hline Gene (accession No.) & Forward primer $\left(5^{\prime} \rightarrow 3^{\prime}\right)$ & Reverse primer $\left(5^{\prime} \rightarrow 3^{\prime}\right)$ \\
\hline COX IV (RNCOX4) & agcctaattggcaagmgagc & gtcgtagtcccacttggc \\
\hline CPT1 $(\mathrm{NM} 013200.1)$ & gcaaactggaccgagaagag & aagaaagcagcacgttcgat \\
\hline CPT2 (NM012930.1) & agacgctcagcttcaacctc & catmgctgcytctttggt \\
\hline CS (AF461496) & gaaacatcrgttcttgatcc & gtgtattccagatgtagtcwcgtaa \\
\hline Cyt $c$ (NM012839) & cgggacgtctccetaaga & gctattaggtctgccetttc \\
\hline$H O A D(\mathrm{NM} 130826.1)$ & tggagtcaaaggggatgtggcagt & agcagcaggcacacccaccatttt \\
\hline$L C A D(\mathrm{BC} 062006.1)$ & tggcattagcetctttttgg & tggatgtgtgcgactgtttt \\
\hline$M C A D(\mathrm{NM} 016986.1)$ & atttggggaggatgacggag & atgaaactccttggtgctcc \\
\hline NRF1 (XM231566) & gcatgctgaaactctcccta & ctgcagtcccattcttcceca \\
\hline$N R F 2 \alpha(\mathrm{XM} 344002.1)$ & aatgtgtaagccaggccata & tgagtgtggtgaggtctata \\
\hline$P G C-1 \alpha(\mathrm{NM} 013196.1)$ & cacaactcctcctcataaagc & tcattactgaagtcgecatc \\
\hline PPAR $\alpha$ (NM013196.1) & gaagaacttcaayatgaacaaggt & cagcatccertctttgttca \\
\hline$P P A R \beta$ (NM013141.1) & acaacgctatccgctttgga & tcgaacttgggctcaatgat \\
\hline Sirt1 (XM228146) & ttggcaccgatcctcgaac & cccagctccagtcagaactat \\
\hline
\end{tabular}

\section{Nucleic acids}

DNA measurements were made on enzyme homogenates. Aliquots were digested overnight at $55^{\circ} \mathrm{C}$ using proteinase $\mathrm{K}(0.2 \mathrm{mg} / \mathrm{mL})$ in $(\mathrm{mmol} / \mathrm{L}) 100 \mathrm{NaCl}, 10$ Tris- $\mathrm{HCl}(\mathrm{pH} 8.0)$, 25 EDTA, and $0.5 \%$ SDS ( $\mathrm{pH} 8.0)$. The DNA content of each digest was assayed against DNA standards (1-60 ng of purified genomic DNA) using Pico-Green (Molecular Probes, Eugene, Ore.). The digested homogenates $(2 \mu \mathrm{L})$ and the DNA standards were loaded onto 96-well black plate and incubated for $5 \mathrm{~min}$ with Pico-Green. Fluorescence was measured (excitation $480 \mathrm{~nm}$, emission 520) with a Spectramax Gemini fluorometer (Molecular Devices).

Frozen powdered tissues were weighed, diluted 10-40 times in guanidium thiocyanate, and homogenized using a Polytron homogenizer. RNA was extracted using the acid-phenol chloroform procedure (Moyes et al. 1997). A small volume of the aqueous phase was collected after the first phase separation for total RNA quantification. Total RNA content was quantified using Ribo-Green (Molecular Probes) according to the manufacturer's instructions. The samples and standard (10-200 ng purified tRNA) were loaded onto a 96-well plate, and fluorescence was measured (excitation $480 \mathrm{~nm}$, emission $536 \mathrm{~nm}$ ) on a Spectramax Gemini fluorometer. The remainder of the aqueous layer was further processed to purify RNA suitable for northern blot analysis. Further purification was conducted to obtain mRNA from purified $250 \mu \mathrm{g}$ total RNA using a polyA ${ }^{+}$purist kit (Ambion Inc., Austin, Tex.).

Following denaturation, the purified RNA was separated in a $1 \%$ agarose-formaldehyde gel. The gels were blotted overnight onto a Duralon-UV membrane (Stratagene, La Jolla, Calif.) and UV crosslinked. Specific cDNA probes were generated by reverse transcriptase PCR using rat cDNA and primers designed for each gene (Table 1). Hybridization and phosphorimaging techniques were performed as described previously (McClelland et al. 2004). On total RNA blots, signal intensities were corrected for loading differences by probing for $18 \mathrm{~S}$ (total RNA blots). As an indicator of mitochondrial content that appeared unaffected by aging, we used CS mRNA as a reference gene for poly $\mathrm{A}^{+}$blot analyses. It allowed us to see whether changes in gene expression in putative transcriptional regulators paralleled the mitochondrial content in aging hearts.

\section{Statistical analysis}

Data are presented as mean values \pm the SE. The significance of differences between old and very old individuals $(\alpha<0.05)$ was established using 2 -tailed Student's $t$ tests.

\section{Results and discussion}

Healthy, adult mammalian myocardium relies primarily on fatty acids as metabolic fuels. However, this fuel preference can change during development and pathology. For example, neonatal heart relies to a greater extent on carbohydrate oxidation. In many models, aging myocardium shifts back to the neonatal phenotype, exhibiting reduced activities of fatty acid oxidizing enzymes (Allard et al. 1994; Sambandam et al. 2002), but the extent of such changes appears to be a function of the strain and age of the subject studied (Lipman et al. 1996). Hypertension also leads to a shift in fuel selection, and since ventricular hypertrophy accompanies both hypertension (de las Fuentes et al. 2003; Davila-Roman et al. 2002) and aging (Allard et al. 1994; Sambandam et al. 2002; Hansford and Castro 1982; Finck and Kelly 2002), it is conceivable that the shift away from FAO in aging may be a generalized response to the ventricular hypertrophy seen in cardiopathologies. Most studies of bioenergetic remodeling of tissues focus on a series of transcriptional regulators that control mitochondrial content: NRF1 and NRF2, and the PPAR and PGC-1 gene families. In the present study, we examined the patterns of change in these transcriptional regulators associated with changes in the metabolic properties of the aging myocardium.

As in most studies, aging in these rats was accompanied by ventricular hypertrophy, the relative ventricular mass (grams of ventricle per kilogram of body mass) increasing by $20 \%$ $(P=0.0006$, Table 2$)$. The DNA content of the heart did not change when expressed per gram of ventricle, and when changes in ventricular mass are taken into account the heart of aged rats had $20 \%$ more DNA. Although recent studies 
Table 2. Morphological and molecular characteristics of adult and very old rats.

\begin{tabular}{|c|c|c|}
\hline & Adult & Very old \\
\hline Body weight $(\mathrm{g})^{a}$ & $525.37 \pm 35.69$ & $518.73 \pm 10.42$ \\
\hline Cardiac muscle $(\mathrm{mg})^{a}$ & $1.27 \pm 0.14$ & $1.53 \pm 0.045 *$ \\
\hline Cardiac specific mass ${ }^{a}(\mathrm{mg} / \mathrm{g}$ body weight) & $2.43 \pm 0.10$ & $2.96 \pm 0.09 *$ \\
\hline DNA (mg/g tissue $)^{b}$ & $1.42 \pm 0.10$ & $1.41 \pm 0.06$ \\
\hline RNA (mg/g tissue $)^{b}$ & $1.42 \pm 0.10$ & $1.41 \pm 0.06$ \\
\hline
\end{tabular}

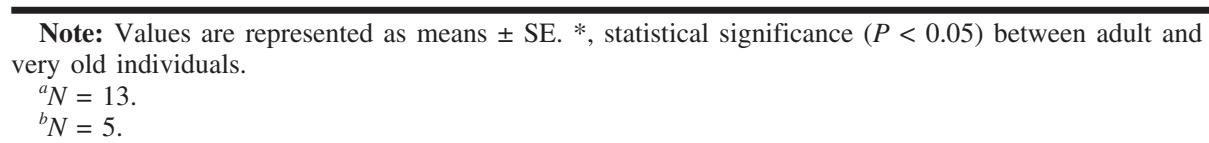

suggest that cardiac muscle has some capacity for hyperplasia (Nadal-Ginard et al. 2003), it is likely that the increase in DNA content is attributable to a proliferation of cells other than cardiomyocytes, particularly fibroblasts. It is thought that the aging rat myocardium experiences a loss of myocytes, hypertrophic growth of the remaining myocytes, and consequently to an overall reduction of the population of myonuclei in the muscle (Kajstura et al. 1996; Swynghedaw et al. 1995).

\section{Mitochondrial enzymes}

Aging causes no more than modest decreases in the specific activities of Krebs cycles and electron transport enzymes (Fig. 1A). Even where differences were significant (CS, aconitase) the reductions were only $10 \%-15 \%$. Thus, there was also a near preservation of the stoichiometric relations between these mitochondrial enzymes. These modest effects of aging on mitochondrial enzyme activities are consistent with previous studies (Iemitsu et al. 2002; Bodyak et al. 2002). In contrast, the enzymes of FAO displayed greater variation. Notably, HOAD activity decreased by about $50 \%$ $(P=0.03)$, whereas CPT activities tended to increase, a pattern similar to that seen in previous studies (Hansford 1978, Hansford and Castro 1982), while LCAD activity was unaffected.

Next, we compared the expression profiles with the enzyme changes. The total RNA/g levels did not change with aging (Table 2), which is consistent with previous studies (Besse et al. 1993). In the case of some enzymes with simple subunit structure, it is meaningful to compare the mRNA levels directly with enzymatic activities. Citrate synthase is a homodimer, and the mRNA for the subunit was unaffected by aging (Fig. 1B), whereas its activity declined significantly but only by $10 \%$ (Fig. 1A). We saw little change in COX activity (13 subunits), and there was no significant change in the mRNA levels for 1 of its nuclear-encoded subunits (COX IV) or its substrate (cytochrome c).

The mRNA levels for a collection of 5 genes involved in mitochondrial $\beta$-oxidation changed in parallel, each decreasing by about $30 \%$ with age. Although only the changes in HOAD were statistically significant $(P<0.05)$, there was a clear similarity in the patterns. Furthermore, the mRNA levels for these other enzymes strongly correlated with HOAD (Fig. 1C). In other words, individuals that had low HOAD mRNA levels also had low mRNA levels for the other enzymes of FAO. This strongly supports the concept of a network of genes regulated in parallel. A global downregulation of the transcript levels of FAO enzymes has been reported in induced cardiac hypertrophy and aging studies (Sack et al. 1997; Iemitsu et al. 2002).
Collectively, these data suggest that the genes for enzymes of FAO are regulated in parallel in adult and aging myocardium. However, it is noteworthy that the changes in mRNA levels did not always reflect the enzyme activities. For example, CPT1 and CPT2 mRNA levels appeared to decline whereas CPT enzymatic activity did not change; thus the ratio of means of enzyme activities to mRNA levels increased by about $50 \%$. In contrast to HOAD, in which mRNA and enzyme decreased to a similar extent, LCAD enzyme activity remained normal when transcripts appeared to decline (though this decrease was not statistically significant). These data suggest a potential role for post-transcriptional regulation of these gene products, as is seen in cardiac failure models (Sack and Kelly 1998; Lehman and Kelly 2002).

When we analyzed the mRNA levels of transcriptional regulators, several interesting patterns emerged. The genes encoding the basic elements of mitochondrial oxidative metabolism (Krebs cycle enzymes and the electron transport chain) are thought to be controlled by PGC- $1 \alpha$, acting through the nuclear respiratory factors. Since these enzymes did not change, we anticipated that the expression of NRF1 and NRF2 would also remain unchanged. Surprisingly, the mRNA levels of NRF1 increased by $33 \%(P<0.05)$ and NRF $2 \alpha$ by $24 \%(P=0.06)$ (Fig. $2 \mathrm{~A})$. An increase in NRF1 with aging has also been reported in skeletal muscle (Lezza et al. 2001). These observations raise 2 questions. The first question is why mRNA was elevated for these transcription factors. The expression of the NRF1 and NRF2 genes are regulated in response to the levels or activity of PGC- $1 \alpha$ (Wu et al. 1999; Mootha et al. 2004). In this study there was no corresponding increase in PGC- $1 \alpha$ mRNA levels. In fact, the levels of the NRFs increased by $60 \%-80 \%$ when expressed relative to their putative regulator, PGC- $1 \alpha$. This does not in itself rule out a role of PGC- $1 \alpha$ in controlling the genes for NRF1 and NRF2 $\alpha$ : it is possible that PGC- $1 \alpha$ transactivational capacity is stimulated despite a reduction in PGC- $1 \alpha$ synthesis, which is suggested by the mRNA pattern. The PGC- $1 \alpha$ protein may have been activated through post-transcriptional mechanisms (Puigserver et al. 2001; Teyssier et al. 2005). An alternative possibility is that NRF1 and NRF $2 \alpha$ genes were stimulated by other transcriptional regulators. A similar dysynchrony is seen in liver disease, in which NRF1 increases despite decreases in PGC-1 $\alpha$ (Chen et al. 2005).

The second question raised in light of the elevated NRF1 and NRF2 levels is why there was no increase in the expression of genes thought to be regulated by these transcription factors. For example, neither cytochrome c nor COXIV demonstrated an increase in mRNA levels, and each is regulated by NRF1 and (or) NRF2 (Evans and Scarpulla 1989; Carter et al. 


\section{(A) Enzymes activities}

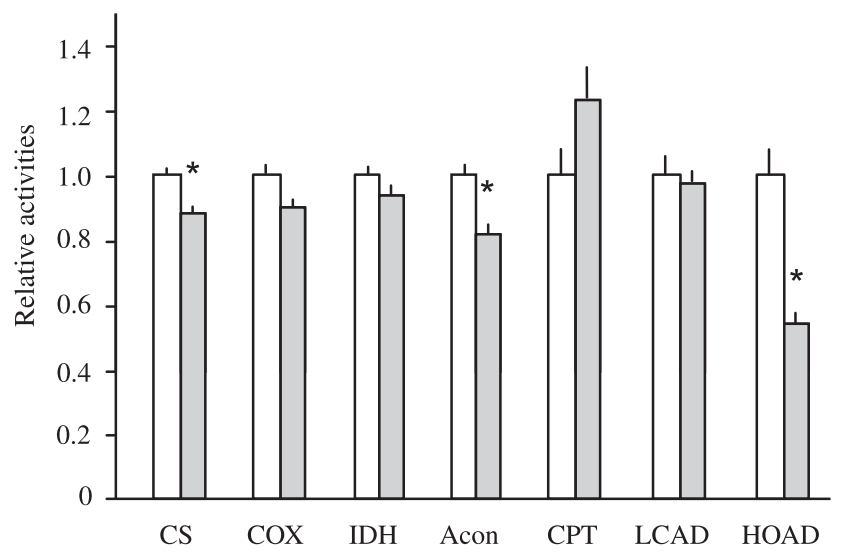

(B) Transcripts

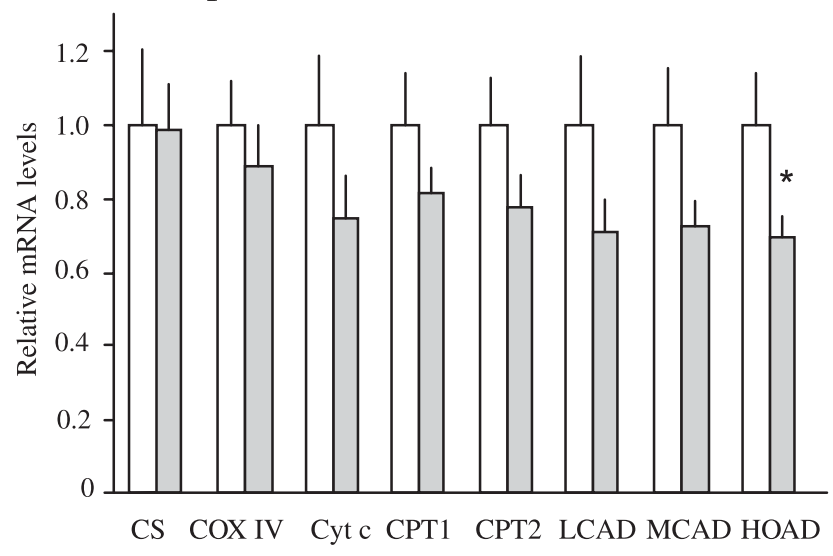

(C) Correlations

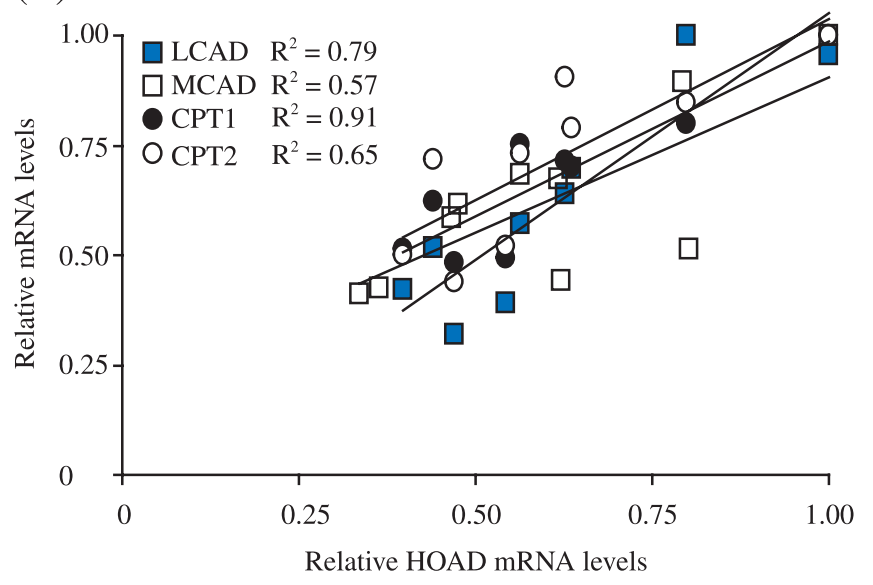

1992). If elevated NRF mRNA levels do, in fact, increase NRF synthesis, then it is possible that target genes escape the effects through post-translational inhibition of its DNA binding activity, as has been shown for both NRF1 (Gugneja and Scarpulla 1997) and NRF2 (Martin et al. 1996; Vallejo et al. 2000).

\section{The PPAR axis}

The mRNA analyses suggest that the expression for 5 genes of FAO were regulated in parallel. Although only some of these genes have been studied in detail, most genes for enzymes of FAO are regulated through a PPAR-PGC- $1 \alpha$
Fig. 1. Catalytic activities and mRNA levels of mitochondrial enzymes in the cardiac muscle of adult and very old rats. (A) Specific activities (units/g tissue) of LCAD, HOAD, CPT, IDH, ACON, CS and COX in adult (open bars) and very old (gray bars) rats. Data are expressed as means + SE and are scaled to be presented relative to the mean of the values for adult myocardium $(N=5)$. A value of 1 corresponds to $102 \mathrm{U} \mathrm{CS}, 98 \mathrm{U}$ COX, 4 U IDH, 7.8 U ACON, 0.7 U CPT, 2.3 U LCD, and $54 \mathrm{U}$ HOAD. (B) The mRNA levels for selected enzymes of mitochondrial metabolism, based on northern blots of $20 \mu \mathrm{g}$ total RNA and expressed once corrected against 18S rRNA and normalized to the adult values (mean adult value arbitrarily set at 1.0$)$. An asterisk (*) over bars from very old animals identifies a significant difference from adult $(P<0.05)$ as revealed by 2 -tailed Student's $t$ test ( $N=5$ for each age group and gene except for CPT1, CPT2, and LCAD, where $N=4$ in very old animals). (C) Relations between mRNA levels of HOAD and those of other enzymes of fatty acid oxidation, including both adult and very old animals.

pathway (Aoyama et al. 1998; Djouadi et al. 1999; Barger and Kelly 2000; Finck and Kelly 2002; Lehman and Kelly 2002; Gilde and van Bilsen 2003). PPAR $\alpha$ and $\delta$ are known to have overlapping roles in activating FAO, as demonstrated through the use of PPAR $\alpha$ null mice and ligandspecific activation experiments (Muoio et al. 2002; Cheng et al. 2004). However, it is unclear whether a cross-talk exists between the 2 nuclear receptors and whether they regulate cardiac FAO homeostasis independently. For example, a differential affinity for metabolic genes and a competition between the 2 transcriptional regulators could be a mechanism for the differential regulation of the FAO genes. In our study, PPAR $\alpha$ and PGC- $1 \alpha$ appeared to decline in parallel, such that the ratio of the 2 was highly conserved within and between groups. In contrast, PPAR $\beta / \delta$ was relatively unaffected by aging (Fig. 2B). Although the apparent declines in PPAR $\alpha$ and PGC- $1 \alpha$ were not significant, it is possible that we had insufficient power to show that this minor decline was statistically significant. However, it is noteworthy that there was little correlation between the mRNA levels of HOAD and these transcriptional regulators (PGC-1 $\alpha$, PPAR $\alpha$, PPAR $\beta$ : data not shown), unlike the situation with other fatty acid oxidizing enzymes (Fig. 1C).

While the regulation of FAO genes is normally focused on the PPAR-PGC1 axis, other transcriptional regulators have been implicated in remodelling myocardial energetics. For example, part of the change in medium-chain fatty acyl-CoA dehydrogenase (MCAD) expression during cardiac hypertrophy is attributed to changes in the interaction of the MCAD promoter with the orphan nuclear receptor COUP-TF 1 (chicken ovalbumin upstream promoter transcription factor I) and Sp1 family (Sack et al. 1997).

\section{Other transcriptional regulators}

This work focused on the NRF and PPAR transcriptional regulators, but recently another transcriptional regulator has been shown to interact with PGC- $1 \alpha$ to control metabolic gene expression. Sirt1 is the mammalian homologue of Sir2, a yeast histone deacetylase that has an important role in controlling gene expression during cellular aging (Kaeberlein 
Fig. 2. Transcript levels for transcriptional regulators of bioenergetic genes in the cardiac muscle of adult and very old rats. (A) RNA levels were determined from blots of $5 \mu \mathrm{g}$ polyA ${ }^{+}$extracted from total RNA of heart tissue from $N=5$ adult (open bars) and $N=5$ very old (gray bars) hearts. The bars represent mean $( \pm \mathrm{SE})$ steadystate mRNA levels. As citrate synthase (CS) is an indicator of mitochondrial content and CS mRNA was not significantly affected by age (see Table 1), CS was used as a loading reference. Corrected data were expressed once normcalized to the adult values (mean adult value arbitrarily set at 1.0). (B) The mRNA levels for each gene regulatory protein in A was expressed relative to PGC- $1 \alpha(N=5$ in each age group). An asterisk $(*)$ over bars from very old animals identifies a significant difference from adult $(P<0.05)$ as revealed by 2 -tailed Student's $t$ test.

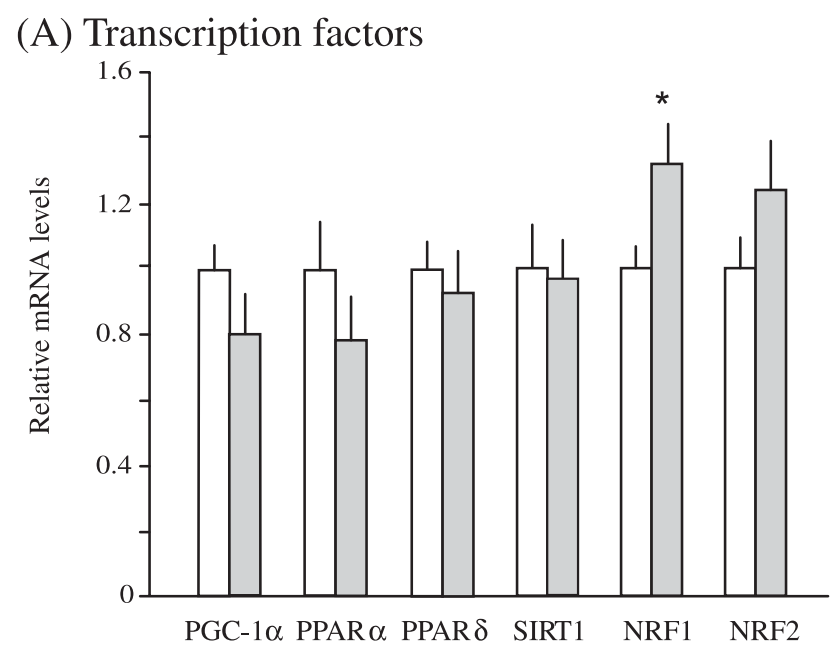

(B) Transcription factors ratios

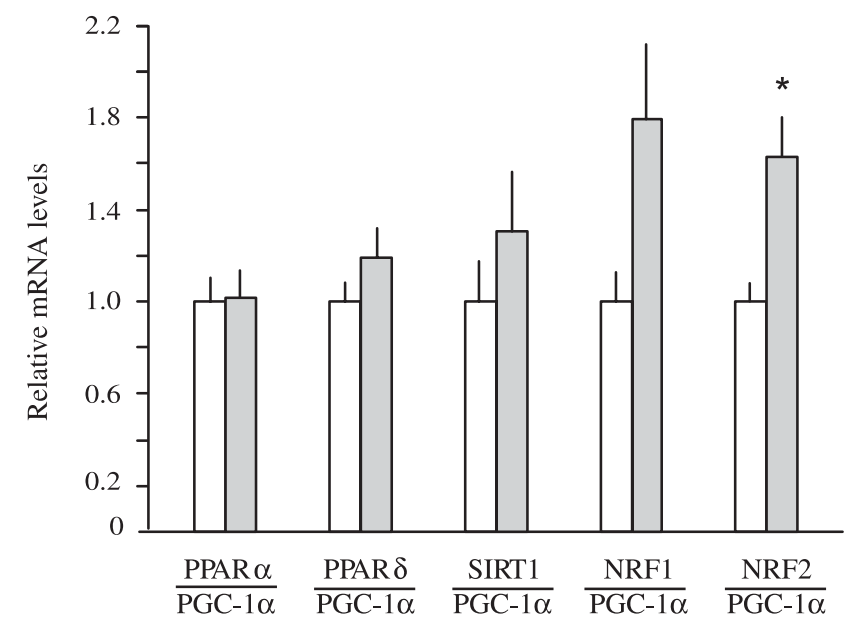

et al. 1999). Sirt1 has recently been shown to act through PGC- $1 \alpha$ to control the expression of glycolytic genes (Rodgers et al. 2005). In this study, Sirt1 transcript levels were unchanged in response to aging.

These studies have focused on control of the bioenergetic remodelling with aging, but other aspects of myocardial function change with age. The changes in contractile protein are thought to be regulated by thyroid hormone and retinoic acid receptors (Long et al. 1999; Iemitsu et al. 2004). These nuclear hormone receptors can act as binding partners with PPARs and NRF1, and their potential role in the control of mitochondrial gene expression is unclear.

In summary, we explored the relations between mitochondrial enzymes and transcriptional regulators in aging rat myocardium. There was a general retention of levels and stoichiometries in enzymes of the Krebs cycle and electron transport. Whereas the mRNA patterns for Krebs cycle enzymes and electron transport proteins are consistent with transcriptional regulation, the levels of 2 putative transcriptional regulators (NRF1 and NRF2) increase with age. The FAO enzymes showed more variable responses in terms of catalytic activity, yet the mRNA for these enzymes declined in parallel. Our results suggest that transcriptional regulation is important but not the only route to control bioenergetic enzyme levels in the context of aging.

\section{Acknowledgements}

We thank Dr. Li Cui, Dr. Yan Ju, and Margarita TrejoMorales for assistance with tissue harvesting. Funding for this research was provided by operating grants from the Natural Sciences and Engineering Research Council of Canada (CDM) and the National Institutes of Health (OMC), and salary awards from the Heart and Stroke Research Corporation of Canada (GBM) and the American Federation of Aging Research (CNL).

\section{References}

Allard, M.F., Schonekess, B.O., Henning, S.L., English, D.R., and Lopaschuk, G.D. 1994. Contribution of oxidative metabolism and glycolysis to ATP production in hypertrophied hearts. Am. J. Physiol. 267: H742-H750.

Aoyama, T., Peters, J.M., Iritani, N., Nakajima, T., Furihata, K., Hashimoto, T., and Gonzalez, F.J. 1998. Altered constitutive expression of fatty acid-metabolizing enzymes in mice lacking the peroxisome proliferator-activated receptor alpha (PPARalpha). J. Biol. Chem. 273: 5678-5684.

Barger, P.M., and Kelly, D.P. 1999. Fatty acid utilization in the hypertrophied and failing heart: molecular regulatory mechanisms. Am. J. Med. Sci. 318: 36-42.

Barger, P.M., and Kelly, D.P. 2000. PPAR signaling in the control of cardiac energy metabolism. Trends Cardiovasc. Med. 10: 238-245.

Besse, S., Assayag, P., Delcayre, C., Carre, F., Cheav, S.L., Lecarpentier, Y., and Swynghedauw, B. 1993. Normal and hypertrophied senescent rat heart: mechanical and molecular characteristics. Am. J. Physiol. 265: H183-H190.

Bodyak, N., Kang, P.M., Hiromura, M., Sulijoadikusumo, I., Horikoshi, N., Khrapko, K., and Usheva, A. 2002. Gene expression profiling of the aging mouse cardiac myocytes. Nucleic Acids Res. 30: 3788-3794.

Carter, R.S., Bhat, N.K., Basu, A., and Avadhani, N.G. 1992. The basal promoter elements of murine cytochrome c oxidase subunit IV consist of tandemly duplicated ETS motifs that bind to GABP-related transcription factors. J. Biol. Chem. 267: 23418-23426.

Chen, C.H., Nagayama, K., Enomoto, N., Miyasaka, Y., Kurosaki, M., Sakamoto, N. et al. 2005. Enhancement of mitochondrial gene expression in the liver of primary biliary cirrhosis. Hepatol. Res. 31: 24-30.

Cheng, L., Ding, G., Qin, Q., Xiao, Y., Woods, D., Chen, Y.E., and Yang, Q. 2004. Peroxisome proliferator-activated receptor delta 
activates fatty acid oxidation in cultured neonatal and adult cardiomyocytes. Biochem. Biophys. Res. Commun. 313: 277-286.

Davila-Roman, V.G., Vedala, G., Herrero, P., de las Fuentes, L., Rogers, J.G., Kelly, D.P., and Gropler, R.J. 2002. Altered myocardial fatty acid and glucose metabolism in idiopathic dilated cardiomyopathy. J. Am. Coll. Cardiol. 40: 271-277.

de las Fuentes, L., Herrero, P., Peterson, L.R., Kelly, D.P., Gropler, R.J., and Davila-Roman, V.G. 2003. Myocardial fatty acid metabolism: independent predictor of left ventricular mass in hypertensive heart disease. Hypertension, 41: 83-87.

Djouadi, F., Brandt, J.M., Weinheimer, C.J., Leone, T.C., Gonzalez, F.J., and Kelly, D.P. 1999. The role of the peroxisome proliferatoractivated receptor alpha (PPAR alpha) in the control of cardiac lipid metabolism. Prostaglandins Leukotrienes Essent. Fatty Acids, 60: $339-343$.

Evans, M.J., and Scarpulla, R.C. 1989. Interaction of nuclear factors with multiple sites in the somatic cytochrome c promoter. Characterization of upstream NRF-1, ATF, and intron Sp1 recognition sequences. J. Biol. Chem. 264: 14361-14368.

Finck, B.N., and Kelly, D.P. 2002. Peroxisome proliferator-activated receptor alpha (PPARalpha) signaling in the gene regulatory control of energy metabolism in the normal and diseased heart. J. Mol. Cell. Cardiol. 34: 1249-1257.

Gardner, P., Nguyen, D., and White, C. 1994. Aconitase is a sensitive and critical target of oxygen poisoning in cultured mammalian cells and in rat lungs. Proc. Natl. Acad. Sci. U.S.A. 91: 12248-12252.

Gilde, A.J., and van Bilsen, M. 2003. Peroxisome proliferatoractivated receptors (PPARS): regulators of gene expression in heart and skeletal muscle. Acta. Physiol. Scand. 178: 425-434.

Gugneja, S., and Scarpulla, R.C. 1997. Serine phosphorylation within a concise amino-terminal domain in nuclear respiratory factor 1 enhances DNA binding. J. Biol. Chem. 272: 18 732-18 739.

Hansford, R.G. 1978. Lipid oxidation by heart mitochondria from young adult and senescent rats. Biochem. J. 170: 285-295.

Hansford, R.G., and Castro, F. 1982. Age-linked changes in the activity of enzymes of the tricarboxylate cycle and lipid oxidation, and of carnitine content, in muscles of the rat. Mech. Ageing Dev. 19: 191-200.

Iemitsu, M., Miyauchi, T., Maeda, S., Tanabe, T., Takanashi, M., Irukayama-Tomobe, Y. et al. 2002. Aging-induced decrease in the PPAR-alpha level in hearts is improved by exercise training. Am. J. Physiol. Heart Circ. Physiol. 283: H1750-H1760.

Iemitsu, M., Miyauchi, T., Maeda, S., Tanabe, T., Takanashi, M., Matsuda, M., and Yamaguchi, I. 2004. Exercise training improves cardiac function-related gene levels through thyroid hormone receptor signaling in aged rats. Am. J. Physiol. 286: H1696-1705.

Kaeberlein, M., McVey, M., and Guarente, L. 1999. The SIR2/3/4 complex and SIR2 alone promote longevity in Saccharomyces cerevisiae by two different mechanisms. Genes Dev. 13: 2570-2580.

Kajstura, J., Cheng, W., Sarangarajan, R., Li, P., Li, B., Nitahara, J.A. et al. 1996. Necrotic and apoptotic myocyte cell death in the aging heart of Fischer 344 rats. Am. J. Physiol. 271: H1215-H1228.

Knutti, D., and Kralli, A. 2001. PGC-1, a versatile coactivator. Trends Endocrinol. Metab. 12: 360-365

Leary, S.C., Michaud, D., Lyons, C.N., Hale, T.M., Bushfield, T.L., Adams, M.A., and Moyes, C.D. 2002. Bioenergetic remodeling of heart during treatment of spontaneously hypertensive rats with enalapril. Am. J. Physiol. Heart Circ. Physiol. 283: H540-H548.

Lee, C.K., Allison, D.B., Brand, J., Weindruch, R., and Prolla, T.A. 2002. Transcriptional profiles associated with aging and middle age-onset caloric restriction in mouse hearts. Proc. Natl. Acad. Sci. U.S.A. 99: 14988-14993.

Lehman, J.J., and Kelly, D.P. 2002. Gene regulatory mechanisms governing energy metabolism during cardiac hypertrophic growth. Heart Failure Rev. 7: 175-185.

Lezza, A.M., Pesce, V., Cormio, A., Fracasso, F., Vecchiet, J., Felzani, G. et al. 2001. Increased expression of mitochondrial transcription factor A and nuclear respiratory factor-1 in skeletal muscle from aged human subjects. FEBS Lett. 501: 74-78.

Lipman, R.D., Chrisp, C.E, Hazzard, D.G., and Bronson, R.T. 1996. Pathologic characterization of brown Norway, brown Norway $\mathrm{x}$ Fischer 344, and Fischer 344 x brown Norway rats with relation to age. J. Gerontol. A Biol. Sci. Med. Sci. 51: B54-B59.

Long, X., Boluyt, M.O., O’Neill, L., Zheng, J.S., Wu, G., Nitta, Y.K. et al. 1999. Myocardial retinoid X receptor, thyroid hormone receptor, and myosin heavy chain gene expression in the rat during adult aging. J. Gerontol. 54: B23-B27.

Martin, M.E., Chinenov, Y., Yu, M., Schmidt, T.K., and Yang, X.Y. 1996. Redox regulation of GA-binding protein-alpha DNA binding activity. J. Biol. Chem. 271: 25617-25623.

McClelland, G.B., Kraft, C.S., Michaud, D., Russell, J.C., Mueller, C.R., and Moyes, C.D. 2004. Leptin and the control of respiratory gene expression in muscle. Biochim. Biophys. Acta, 1688: 86-93.

Mootha, V.K., Handschin, C., Arlow, D., Xie, X., St. Pierre, J., Sihag, S. et al. 2004. Erralpha and Gabpa/b specify PGC-1alphadependent oxidative phosphorylation gene expression that is altered in diabetic muscle. Proc. Natl. Acad. Sci. U.S.A. 101: 6570-6575.

Moyes, C.D., Mathieu-Costello, O.A., Tsuchiya, N., Filburn, C., and Hansford, R.G. 1997. Mitochondrial biogenesis during cellular differentiation. Am. J. Physiol. 272: C1345-C1351.

Muoio, D.M., Maclean, P.S., Lang, D.B., Li, S., Houmard, J.A., Way, J.M. et al. 2002. Fatty acid homeostasis and induction of lipid regulatory genes in skeletal muscles of peroxisome proliferatoractivated receptor (PPAR) $\alpha$ knock-out mice. J. Biol. Chem. 277: 26089-26097.

Nadal-Ginard, B., Kajstura, J., Leri, A., and Anversa, P. 2003. Myocyte death, growth, and regeneration in cardiac hypertrophy and failure. Circ. Res. 92: 139-150.

Puigserver, P., and Spiegelman, B.M. 2003. Peroxisome proliferatoractivated receptor-gamma coactivator 1 alpha (PGC-1 alpha): transcriptional coactivator and metabolic regulator. Endocr. Rev. 24: 78-90.

Puigserver, P., Rhee, J., Lin, J., Wu, Z., Yoon, J.C., Zhang, C.Y. et al. 2001. Cytokine stimulation of energy expenditure through p38 MAP kinase activation of PPARgamma coactivator-1. Mol. Cell. 8: 971-982.

Rodgers, J.T., Lerin, C., Haas, W., Gygi, S.P., Spiegelman, B.M., and Puigserver, P. 2005. Nutrient control of glucose homeostasis through a complex of PGC-1alpha and SIRT1. Nature (London), 434: 113-118.

Sack, M.N., and Kelly, D.P. 1998. The energy substrate switch during development of heart failure: gene regulatory mechanisms. Int. J. Mol. Med. 1: 17-24.

Sack, M.N., Disch, D.L., Rockman, H.A., and Kelly, D.P. 1997. A role for $\mathrm{Sp}$ and nuclear receptor transcription factors in a cardiac hypertrophic growth program. Proc. Nat. Acad. Sci. U.S.A. 94: 6438-6443.

Sambandam, N., Lopaschuk, G.D., Brownsey, R.W., and Allard, M.F. 2002. Energy metabolism in the hypertrophied heart. Heart Failure Rev. 7: 161-173.

Swynghedaw, B., Besse, S., Assayag, P., Carre, F., Chevalier, B., Charlemagne, D. et al. 1995. Molecular and cellular biology of 
the senescent hypertrophied and failing heart. Am. J. Cardiol. 76: 2D-7D.

Teyssier, C., Ma, H., Emter, R., Kralli, A., and Stallcup, M.R. 2005. Activation of nuclear receptor coactivator PGC-1 1 alpha\} by arginine methylation. Genes Dev. 19: 1466-1473.

Vallejo, C.G., Escriva, H., and Rodriguez-Pena, A. 2000. Evidence of tissue-specific, post-transcriptional regulation of NRF-2 expression. Biochimie, 82: 1129-1133.

Van der Vusse, G.J., Glatz, J.F., Stam, H.C., and Reneman, R.S. 1992. Fatty acid homeostasis in the normoxic and ischemic heart. Physiol. Rev. 72: 881-940.
Wanagat, J., Wolff, M.R., and Aiken, J.M. 2002. Age-associated changes in function, structure and mitochondrial genetic and enzymatic abnormalities in the Fischer 344 x Brown Norway $F_{1}$ hybrid rat heart. J. Mol. Cell Cardiol. 34: 17-28.

Wu, Z., Puigserver, P., Andersson, U., Zhang, C., Adelmant, G., Mootha, V. et al. 1999. Mechanisms controlling mitochondrial biogenesis and respiration through the thermogenic coactivator PGC-1. Cell, 98: 115-124. 